Review began 01/05/2022 Review ended 02/20/2022 Published 02/22/2022

(c) Copyright 2022

Tanaka et al. This is an open access article distributed under the terms of the Creative Commons Attribution License CC-BY 4.0., which permits unrestricted use, distribution, and reproduction in any medium, provided the original author and source are credited.

\title{
Threat of Staphylococcus aureus Pneumonia in Severe COVID-19 Patients
}

\author{
Shuichi Tanaka ${ }^{1}$, Koichiro Yamamoto ${ }^{1}$, Hideharu Hagiya ${ }^{1}$, Kou Hasegawa $^{1}$, Fumio Otsuka ${ }^{1}$ \\ 1. General Medicine, Okayama University Graduate School of Medicine, Dentistry and Pharmaceutical Sciences, \\ Okayama, JPN
}

Corresponding author: Hideharu Hagiya, hagiya@okayama-u.ac.jp

\begin{abstract}
Coronavirus disease 2019 (COVID-19) has been spreading worldwide with unprecedented rapidity. Staphylococcus aureus is reported to frequently cause bacterial complications in patients with COVID-19. We herein present two additional cases of $S$. aureus pneumonia involving such patients. The first case was an obese 48 -year-old man without any particular underlying diseases. The second case was another patient, a 72-year-old man, with hypertension, dyslipidemia, and steatohepatitis. Both patients developed methicillinsusceptible S. aureus pneumonia in the clinical course of COVID-19, to which antibiotic therapy with cefazolin was effectively administered. Through these cases, we emphasize that $S$. aureus secondary infections should be well cared with a high degree of caution in a case of critically ill COVID-19 patients.
\end{abstract}

Categories: Emergency Medicine, Infectious Disease, Pulmonology

Keywords: ventilation, superinfection, pneumonia, staphylococcus aureus, coronavirus disease 2019

\section{Introduction}

Coronavirus disease 2019 (COVID-19), caused by severe acute respiratory syndrome coronavirus 2 (SARSCoV-2), has been affecting the whole world.

Recent literature investigated the incidence of secondary bacterial infections in COVID-19 patients with mechanical ventilation due to acute respiratory distress syndrome [1]. Among 126 cases, $61 \%$ developed bacterial infections such as ventilator-associated pneumonia (VAP), blood stream infections, and urinary tract infections in its order, in which Staphylococcus aureus was the most common pathogen. Especially, methicillin-sensitive $S$. aureus (MSSA) accounted for $30 \%$ of the causative organisms of the respiratory infections. Another literature also suggested $S$. aureus to be the most common etiology of co-infection or superinfection secondary to COVID-19 [2]. We herein present two additional cases of MSSA pneumonia involving patients with severe COVID-19.

\section{Case Presentation}

The first case was an obese 48-year-old man (body mass index, $30.6 \mathrm{~kg} / \mathrm{m}^{2}$ ) without any other underlying diseases. The patient underwent the SARS-CoV-2 polymerase chain reaction (PCR) test and was diagnosed with COVID-19 in other institution before hospitalization in our hospital. On admission, his body temperature was $37.2^{\circ} \mathrm{C}$ and oxygen saturation level was $92 \%$ on $4 \mathrm{~L} / \mathrm{min}$ oxygen supplementation. Laboratory tests revealed elevations of serum levels of C-reactive protein (CRP, $18.7 \mathrm{mg} / \mathrm{dL}$ ), lactate dehydrogenase $(608 \mathrm{U} / \mathrm{L})$, and procalcitonin $(0.44 \mathrm{ng} / \mathrm{mL})$. Chest computed tomography showed bilateral multiple ground-glass opacities, which were compatible with COVID-19 pneumonia. The patient received $250 \mathrm{mg}$ per day of methylprednisolone for three days in combination with $100 \mathrm{mg}$ per day of remdesivir for five days. However, his respiratory condition deteriorated and the patient was intubated on the third day of hospitalization. Thereafter, his general status including the inflammatory markers and the findings on chest X-ray ameliorated (Figure $1 \mathrm{~A}$ ). On the seventh day of hospitalization, however, his sputum appeared purulent and the infiltrate shadows got worse (Figure 1B), accompanying elevated serum levels of CRP (16.3 $\mathrm{mg} / \mathrm{dL})$ and procalcitonin $(0.21 \mathrm{ng} / \mathrm{mL})$. Blood culture was negative. Sputum culture detected a large number of MSSA along with leukocyte migration, leading to the diagnosis of MSSA-induced pneumonia. We treated the patient with $6 \mathrm{~g}$ per day of cefazolin for 10 days. His respiratory condition subsequently ameliorated (Figure 1C), and the patient was discharged.

The second case was a 72-year-old man with hypertension, dyslipidemia, and steatohepatitis. The patient also had a confirmed positive result of SARS-CoV-2 PCR test in other hospital and was transferred to our hospital. Due to deteriorated respiratory condition (Figure $1 D$ ), the patient was intubated and administered with $125 \mathrm{mg}$ per day of methylprednisolone for three days and a single dose of $8 \mathrm{mg}$ per $\mathrm{kg}$ of tocilizumab. Subsequently, his respiratory status and serum inflammatory markers ameliorated. However, on the sixth day, the infiltrate shadows worsened (Figure $1 E$ ) and a purulent sputum emerged, which was positive for MSSA and active leukocytes. Blood culture resulted negative. We made a diagnosis of MSSA-induced pneumonia, to which antibiotic therapy with $6 \mathrm{~g}$ per day of cefazolin for 10 days was effectively 


\section{Cureus}

Case 1
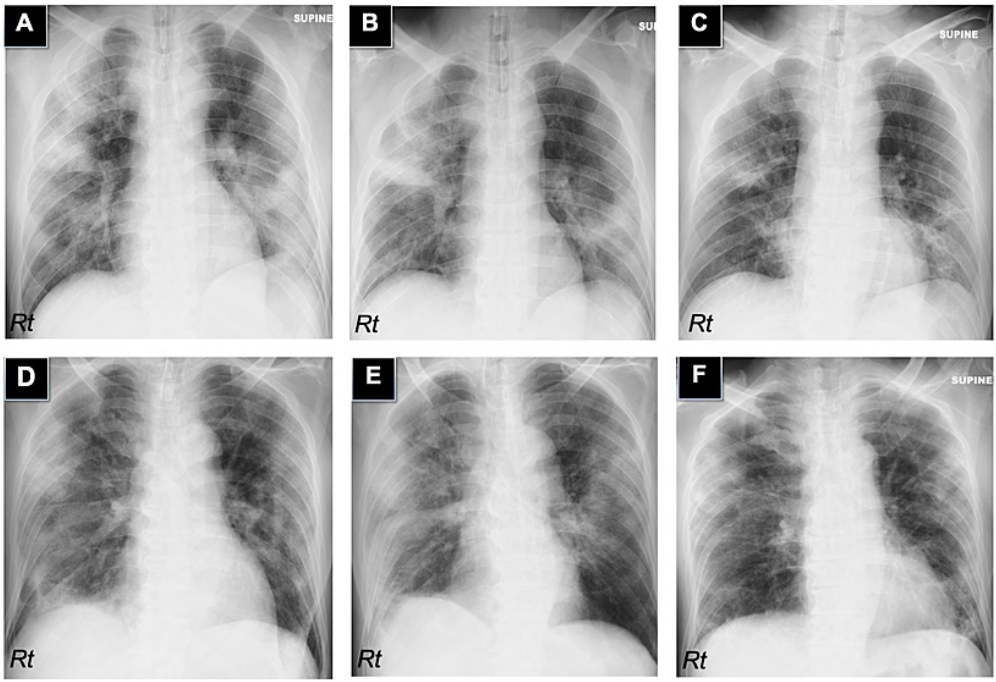

\section{FIGURE 1: Imaging of methicillin-susceptible Staphylococcus aureus pneumonia in two COVID-19 patients.}

Chest $X$-rays of the first case on the fourth day of hospitalization (A), on the seventh day (B, before antibiotic therapy), and on the 16th day (C, after antibiotic therapy). Chest X-rays of the second case on the third day of hospitalization (D), on the sixth day (E, before antibiotic therapy), and on the 16 th day ( $F$, after antibiotic therapy). The infiltration shadows dramatically improved after antimicrobial treatment in both cases.

\section{Discussion}

COVID-19 has been spreading worldwide with unprecedented rapidity. The disease potentially induces various complications, of which secondary bacterial infections should be regarded as the most harmful events [1]. Among various bacterial etiologies, recent literature indicated S. aureus-associated infections to be of great importance. For instance, an observational cohort study investigated the incidence of coinfections and superinfections in hospitalized patients with COVID-19 [2]. Overall, 74 (7.5\%) of 989 patients had bacterial infection secondary to COVID-19, of which 44 cases (59.5\%) were hospital-acquired superinfections complicating clinical course of patients with COVID-19. VAP accounted for $25 \%$ of the nosocomial infections (11/44 cases), in which S. aureus was reportedly the most common causative pathogen (36.4\%). Another retrospective, single-facility study reported that 66 (5.52\%) of 1,251 samples had bacterial infection secondary to COVID-19, of which S. aureus was reportedly the common causative pathogen (24.3\%) [3]. Accordingly, bacterial complications, especially S. aureus-associated infections, do frequently occur in COVID-19 patients, although Gram-negative organisms, including Pseudomonas aeruginosa and Acinetobacter baumanii, are the representatives of VAP pathogens. Notably, $S$. aureus potentially causes various respiratory complications such as necrotizing pneumonia or pneumothorax [4], and, thus, clinicians should be aware of the clinical importance of prevention and management of such cases.

When treating patients with $S$. aureus infections, an empirical coverage against anti-methicillin-resistant $S$. aureus (MRSA) is always an issue to be addressed. Clinicians should be aware of antibiogram, or MRSA isolation rate, at each medical situation, and determine the need of starting broad-spectrum antibiotics. In our hospital, the MRSA isolation rate for nosocomial cases changes approximately at 40-50\% (data not shown). In the present cases, we carefully observed the patient's clinical course without initiating antiMRSA agents.

Antimicrobial stewardship should have a priority even for the patients with COVID-19. To differentiate deterioration of COVID-19 pneumonia and involvement of the secondary bacterial infections, procalcitonin would be of use [5]. Results of a retrospective, single-facility cohort study indicated that, based on a procalcitonin-guided algorithm, antimicrobial usages could be safely reduced in non-critically ill COVID-19 patients [6]. Emergence of antimicrobial resistance is another challenge that the global society is facing, which should be cared even amid the COVID-19 pandemic. 


\section{Conclusions}

We described two severe cases of $S$. aureus pneumonia involving ventilated patients suffering from COVID19. S. aureus is usually not such a common pathogen in VAP. Compiling related literature with our cases, we would like to highlight that $S$. aureus-targeted treatment should be empirically initiated when COVID-19 patients manifest findings suggesting bacterial pneumonia.

\section{Additional Information \\ Disclosures}

Human subjects: Consent was obtained or waived by all participants in this study. Conflicts of interest: In compliance with the ICMJE uniform disclosure form, all authors declare the following: Payment/services info: All authors have declared that no financial support was received from any organization for the submitted work. Financial relationships: All authors have declared that they have no financial relationships at present or within the previous three years with any organizations that might have an interest in the submitted work. Other relationships: All authors have declared that there are no other relationships or activities that could appear to have influenced the submitted work.

\section{References}

1. Risa E, Roach D, Budak JZ, et al.: Characterization of secondary bacterial infections and antibiotic use in mechanically ventilated patients with COVID-19 induced acute respiratory distress syndrome. J Intensive Care Med. 2021, 36:1167-75. 10.1177/08850666211021745

2. Garcia-Vidal C, Sanjuan G, Moreno-García E, et al.: Incidence of co-infections and superinfections in hospitalized patients with COVID-19: a retrospective cohort study. Clin Microbiol Infect. 2021, 27:83-8. 10.1016/j.cmi.2020.07.041

3. Ruiz-Bastián M, Falces-Romero I, Ramos-Ramos JC, de Pablos M, García-Rodríguez J: Bacterial coinfections in COVID-19 pneumonia in a tertiary care hospital: surfing the first wave. Diagn Microbiol Infect Dis. 2021, 101:115477. 10.1016/j.diagmicrobio.2021.115477

4. Chaudhry B, Alekseyev K, Didenko L, Malek A, Ryklin G: Post COVID-19 MSSA pneumonia. SAGE Open Med Case Rep. 2021, 9:2050313X211005996. 10.1177/2050313X211005996

5. Han J, Gatheral T, Williams C: Procalcitonin for patient stratification and identification of bacterial coinfection in COVID-19. Clin Med (Lond). 2020, 20:e47. 10.7861/clinmed.Let.20.3.3

6. Calderon M, Li A, Bazo-Alvarez JC, et al.: Evaluation of procalcitonin-guided antimicrobial stewardship in patients admitted to hospital with COVID-19 pneumonia. JAC Antimicrob Resist. 2021, 3:dlab133. 10.1093/jacamr/dlab133 